\title{
ESTRUTURA E DISTRIBUIÇÃO ESPACIAL DOS GEOAMBIENTES NA PAISAGEM ENTRE A RESERVA PARTICULAR DO PATRIMÔNIO NATURAL (RPPN) FAZENDA SERRA NEGRA E O PARQUE ESTADUAL DO IBITIPOCA
}

\author{
STRUCTURE AND SPATIAL DISTRIBUTION OF LANDSCAPE \\ GEOENVIRONMENT IN BETWEEN PRIVATE NATURAL \\ HERITAGE RESERVE (RPPN) FAZENDA SERRA NEGRA \\ AND THE PARQUE ESTADUAL DO IBITIPOCA
}
ESTRUCTURA Y DISTRIBUCIÓN ESPACIAL DE GEOAMBIENTES EN PAISAJE ENTRE LA RESERVA PRIVADA PATRIMONIO NATURAL (RPPN) FAZENDA SERRA NEGRA Y EL PARQUE ESTADUAL DE IBITIPOCA
Cristina Silva de Oliveira - Universidade Federal de Juiz de Fora - Juiz de Fora - Minas Gerais -Brasil chrisoliveira.jf@gmail.com

\begin{abstract}
Resumo
0 presente trabalho objetivou identificar e caracterizar unidades geoambientais no espaço compreendido entre a Reserva Particular do Patrimônio Natural (RPPN) Fazenda Serra Negra e o Parque Estadual do Ibitipoca. Através do método de superposição dos atributos geoecológicos pode-se identificar o padrão espacial resultante da interação entre os elementos formadores da estrutura da paisagem em cada unidade geoambiental. As análises realizadas no estudo permitiram identificar a comparência de 13 unidades, bem como realçar a importância dessas áreas e suas peculiaridades geoecológicas em um planejamento integrado da paisagem nas áreas de influência de unidades de conservação, fazendo interagir os diversos fatores conflitantes de uso e ocupação da terra.
\end{abstract}

Palavras-chave: Unidades de Conservação, geoecologia da paisagem, unidades geoambientais.

\section{Abstract}

This study aimed to identify and characterize geoenvironmental units in the space between the Private Natural Heritage Reserve (RPPN) Fazenda Serra Negra and Parque Estadual do Ibitipoca. Through the superposition of geoecological attributes method, spatial patterns resulting from the interaction between the forming elements of landscape structure on each geoenvironmental unit could be identified. The analysis performed in this study allowed to identify the appearance of 13 units, as well as highlight the importance of these areas and their rural ecology peculiarities in an integrated landscape planning in the areas of influence of protected areas, making interaction of the different conflicting factors for use and occupation of earth.

Keywords: Conservation Units, geoecology landscape, geoenvironmental units.

\section{Resumen}

Este estudio tuvo como objetivo identificar y caracterizar unidades geoambientales en el espacio situado entre la Reserva Privada del Patrimonio Natural (RPPN) Hacienda Serra Negra y el Parque Estadual Ibitipoca. A traves del método de superposición de los atributos geoecológicos se puede identificar el patrón espacial resultante de la interacción entre los elementos que componen la estructura del paisaje en cada unidad geoambiental. Los análisis realizados en este estudio permitieron identificar la existencia de 13 unidades, así como realzar la importancia de esas áreas y sus peculiaridades geológicas en una planificación integrada del 
paisaje en las zonas de influencia en áreas protegidas, permitiendo la interacción de los diferentes factores en conflicto para el uso y ocupación de tierra.

Palabras-clave: Unidades de Conservación, geoecología del paisaje, unidades geoambientales.

Introdução

Produto de um complexo conjunto de interações entre os fatores abióticos, bióticos e antrópicos, a paisagem compreendida entre a Serra Negra e a Serra do Ibitipoca resguarda características exemplares das ricas, biodiversas e imensuráveis paisagens brasileiras.

Compreendida no domínio tropical atlântico, com formações florestais luxuriantes e em alguns setores, formatada pelos campos rupestres de altitude desenvolvidos em quartzito, essas paisagens evidenciaram ser o meio físico, ecológico e paisagístico mais complexo e difícil do país em relação às ações antrópicas (Ab’Sáber, 2003).

Historicamente essa complexidade é facilmente constatada. $\mathrm{Na}$ Zona da Mata Mineira, a ocupação das terras para a construção de vilas e cidades aliada a implantação de atividades econômicas como a produção de café, a criação de gado e mais recentemente pelos cultivos de eucalipto, modificaram a estrutura da paisagem, engendrando formas de uso diversificadas, dadas principalmente, pela remoção da vegetação original, resultando na fragmentação da paisagem e na sua substituição por florestas secundárias (Valente et al., 2006).

Desta forma, uma paisagem florestal que se mantinha conservada dá lugar a um conjunto de matas desconexas e fragmentadas na paisagem que, por sua vez, pode apresentar um cenário de degradação. Esta, diferente da paisagem florestal conservada, tem uma história que envolve a ação antropogênica e o uso que dela fizeram. Por esse motivo os fragmentos florestais são produtos da intervenção antrópica ao logo da história que modificam ou transformam, direta ou indiretamente, a estrutura e o funcionamento internos das paisagens naturais e podem ser encarados como formas particulares desenvolvidas nela (Turner, 1989).

Para Torres et al. (2012), o homem ao eliminar a interface representada pela cobertura vegetal, altera de forma substancial as relações entre as forças de ação (processos morfogenéticos ou morfodinâmicos) e de reação da formação superficial, gerando desequilíbrios morfológicos ou impactos geoambientais na área de ocorrência. 
Apesar do constatado, foram criados espaços legalmente protegidos que resguardam características naturais relevantes e que têm a função de assegurar a representatividade de amostras significativas e ecologicamente viáveis das diferentes populações, hábitats e ecossistemas do território nacional e das águas jurisdicionais, preservando o patrimônio biológico existente (SNUC, 2000).

No município de Lima Duarte, o Parque Estadual do Ibitipoca e a RPPN Fazenda Serra Negra configuram exemplos desses espaços legalmente protegidos e de grande beleza paisagística (Figura 1). Na área que envolve essas duas unidades de conservação, bem como no seu espaço adjacente, predominam um relevo bastante movimentado arquitetado pelas serras quartzíticas do Ibitipoca, Lima Duarte e Serra Negra. Além disso, destaca-se por apresentar um denso sistema de drenagem com formações de belas corredeiras, cachoeiras e lagos naturais. Outro fator preponderante é a presença imperiosa de fragmentos expressivos e bem preservados do pouco que resta da Mata Atlântica e ecossistemas

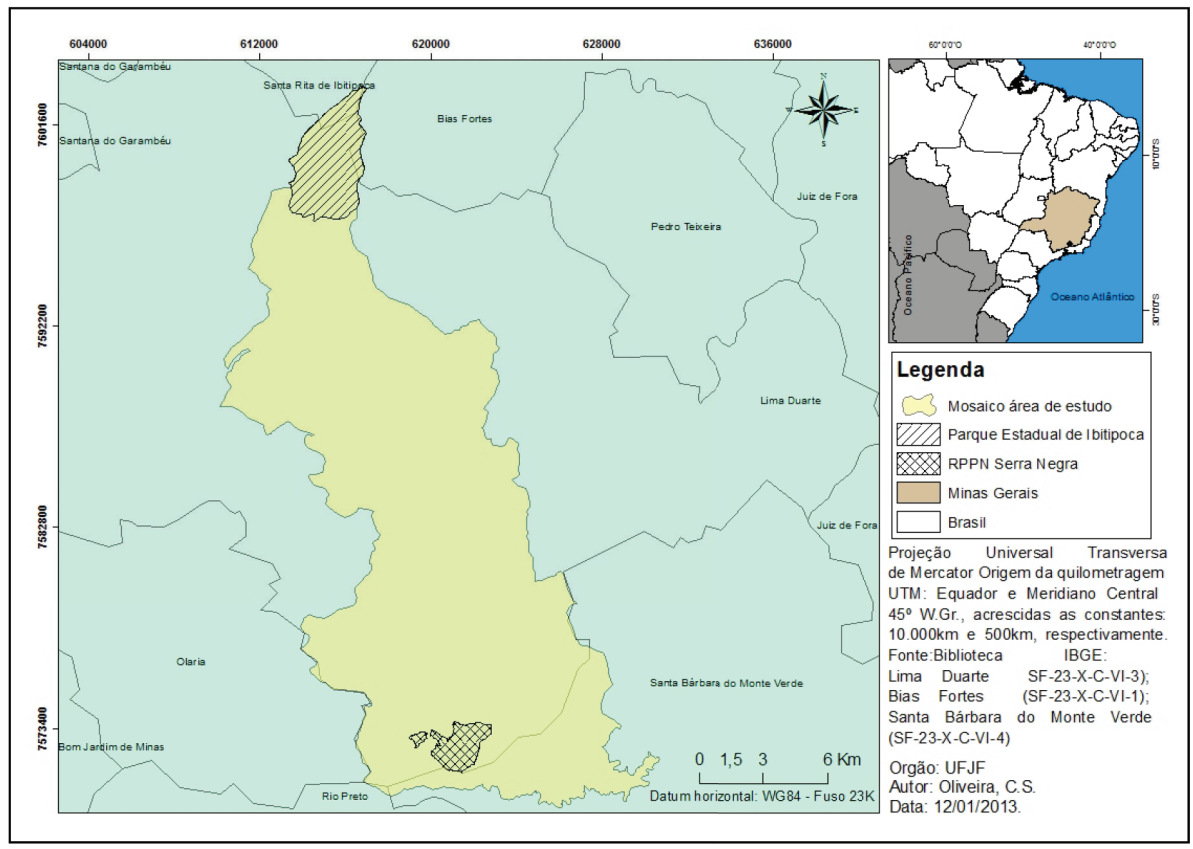

Figura 1 - Localização da área de estudo 
associados, e onde se localiza uma das maiores e mais belas concentrações de cavernas quartzíticas do Brasil.

Diante dessas considerações, fica realçado que o conhecimento dos padrões de organização, sua diversidade espacial e as particularidades de cada paisagem na área de influência das unidades de conservação propiciam a avaliação da estrutura da paisagem e as consequências das intervenções antrópicas na biodiversidade, ao mesmo tempo em que aponta o uso e ocupação potencial e as suas fragilidades.

Partindo dessa premissa, o presente trabalho almeja contribuir com o mapeamento de unidades geoambientais no espaço compreendido entre a Reserva Particular do Patrimônio Natural (RPPN) Fazenda Serra Negra e o Parque Estadual do Ibitipoca, a fim de contribuir com a educação, conservação e planejamento ambiental da área de influencias das unidades de conservação.

\section{Procedimentos metodológicos}

Para a edição dos documentos cartográficos utilizou-se um recorte da imagem de satélite obtida pelo sensor TM/LANDSAT 13 de agosto de 2011, cena de código de órbita/ponto 217/75, com resolução espacial de 30 metros. As imagens foram adquiridas no catálogo de imagens disponível no site do Instituto Nacional de Pesquisas Espaciais (INPE), tendo como critério de seleção a data de interesse, o menor percentual de nuvens e a estação do ano. A partir das imagens do sensor, realizaram-se as combinações das bandas 3, 4, 5 das imagens. O georreferenciamento da imagem foi efetuado com cartas topográficas em formato digital escala 1: 50.000, elaborada pelo Instituto Brasileiro de Geografia e Estatística (IBGE).

No processamento de dados espaciais foi utilizado o software ArcGIS 9.3 (confecção dos mapas temáticos) e ENVI 4.5 (processamento digital de imagens). Os dados vetoriais da hidrografia e sistema viário foram obtidos a partir das cartas topográficas dos municípios de Lima Duarte (SF-23-X-C-VI-3), Bias Fortes (SF-23-X-C-VI-1) e Santa Bárbara do Monte Verde (SF-23-X-C-VI-4), na escala 1:50.000 disponibilizadas pelo IBGE. O mapa geológico e os arquivos vetoriais das estruturas e afloramentos rochosos, foram obtidos através da digitalização do Mapa Geológico de Lima Duarte (Folha SF-23-X-VI), escala 1:100.000 fornecida pela Companhia de Pesquisa de Recursos Minerais (CPRM). 
As informações de hipsometria e declividade foram produzidas pela transformação dos dados vetoriais em dados matriciais. A imagem utilizada foi obtida pelo satélite SRTM (Shuttle Radar Topography Mission), disponibilizados livre e eletronicamente pela EMBRAPA (http://www. relevobr.cnpm.embrapa.br/), resolução espacial de 90 x 90 metros.

A elaboração do mapa de sistemas de relevo teve como base os procedimentos técnico-operacionais propostos pelo Instituto de Pesquisas Tecnológicas (IPT) (1981) no estado de São Paulo. Os principais critérios adotados para a elaboração deste mapeamento foram a declividade dominante das vertentes e amplitude do relevo. Partindo dessa premissa, as formas de relevo foram identificadas, individualizadas e delimitadas a partir da superposição do mapa de declividade e as cartas topográficas do IBGE, na escala 1:50.000. Para auxiliar na análise integrada dos mapas e realçar as variações de relevo da área foi gerada uma imagem de relevo sombreado a partir da Imagem Aster (Advance Space Borne Thermal Emission and Reflection Radiometer) da NASA disponibilizados livre e eletronicamente no site (http:/gdex.cr.usgs.gov/gdex/), resolução espacial de 30 x 30 metros, disponibilizados gratuitamente.

Para mapear a vegetação e o uso da terra na área de estudo utilizou-se a metodologia proposta por Lardosa (2005), que tem como base a classificação digital automática de máxima verossimilhança (MAXVER) associada à interpretação visual, na qual os objetos de interesse foram identificados a partir de elementos de reconhecimento, textura, cor, tonalidade e forma. Além da composição RGB da TM/LANDSAT (bandas 3,4,5) de agosto de 2011 foi utilizadas como apoio ao mapeamento imagens de alta resolução disponibilizadas pelo software Google Earth do ano de 2010.

As tipologias de uso da terra foram definidas de modo a englobar todos os usos presentes na área de estudo, como vegetação arbórea, ocupação urbana, corpos d'água, afloramento rochoso, solo exposto, sombra, conforme orientações metodológicas do Manual técnico de uso da terra do IBGE (2006).

Concomitantemente ao procedimento de interpretação e mapeamento foram realizados trabalhos de campo in locu para aferição de parte das informações visualizadas nas imagens, bem como, analisar o estado de conservação das formações florestais, existência de plantios com espécies exóticas de Eucalyptus nas proximidades das unidades de conservação para posteriormente relacioná-las com aspectos perceptíveis na imagem TM/LANDSAT 5; nessa etapa foi utilizado um GPS (Sistema 
de Posicionamento Global) para a coleta de pontos, que posteriormente foram sobrepostos a imagem de satélite, procedimento este complementado por registros fotográficos. Esses pontos serviram como referência para interpretação e classificação das outras áreas da imagem. O relevo, a vegetação, a ocupação da terra, a presença de corpo d'água, estradas e afloramentos rochosos foram parâmetros permanentemente observados durante o roteiro.

Para a confecção do mapa de unidades geoambientais foi utilizado o método da sobreposição de mapas. Esse método possui forte poder de síntese, embora haja uma limitação no número de camadas que possam ser visualizadas juntas. A premissa geral é a divisão da área em unidades homogêneas, ou seja, agrupar os pontos que tem as mesmas características e funções comuns, portanto a mesma estrutura, conforme proposição de (Santos, 2007). Ao dividir-se a área de estudo em unidades homogêneas, de acordo com as suas características abióticas e bióticas, pode-se inferir as restrições ou favorabilidades destas unidades às diversas intervenções humanas (Vedovello, 2004).

Assim, as unidades geoambientais foram definidas a partir da análise e interpretação conjunta dos aspectos referentes à geologia, relevo, hipsometria, declividade e uso da terra.

\section{Resultados e discussão}

O mosaico de paisagem apresenta uma diversidade e heterogeneidade de geoambientes equivalente à variedade de formas de relevo, de uso e ocupação da terra observados na área. Através do método de superposição dos atributos geoecológicos, como geologia, relevo, hipsometria, declividade, vegetação, hidrografia, uso e ocupação da terra; pode-se identificar o padrão espacial resultante da interação entre os elementos formadores da paisagem em cada unidade geoambiental. Essas unidades foram definidas e identificadas por algarismos romanos, conforme as feições do relevo predominantes.

Dessa forma, verificou-se a comparência de 13 unidades geoambientais segundo as suas especificidades estruturais, conforme Figura 2, são elas: unidade I - planícies de inundação florestadas; unidade II - planície de inundação com vegetação rasteira; unidade III - planície de inundação urbanizada; unidade IV - colinas e morrotes com floresta ombrófila 


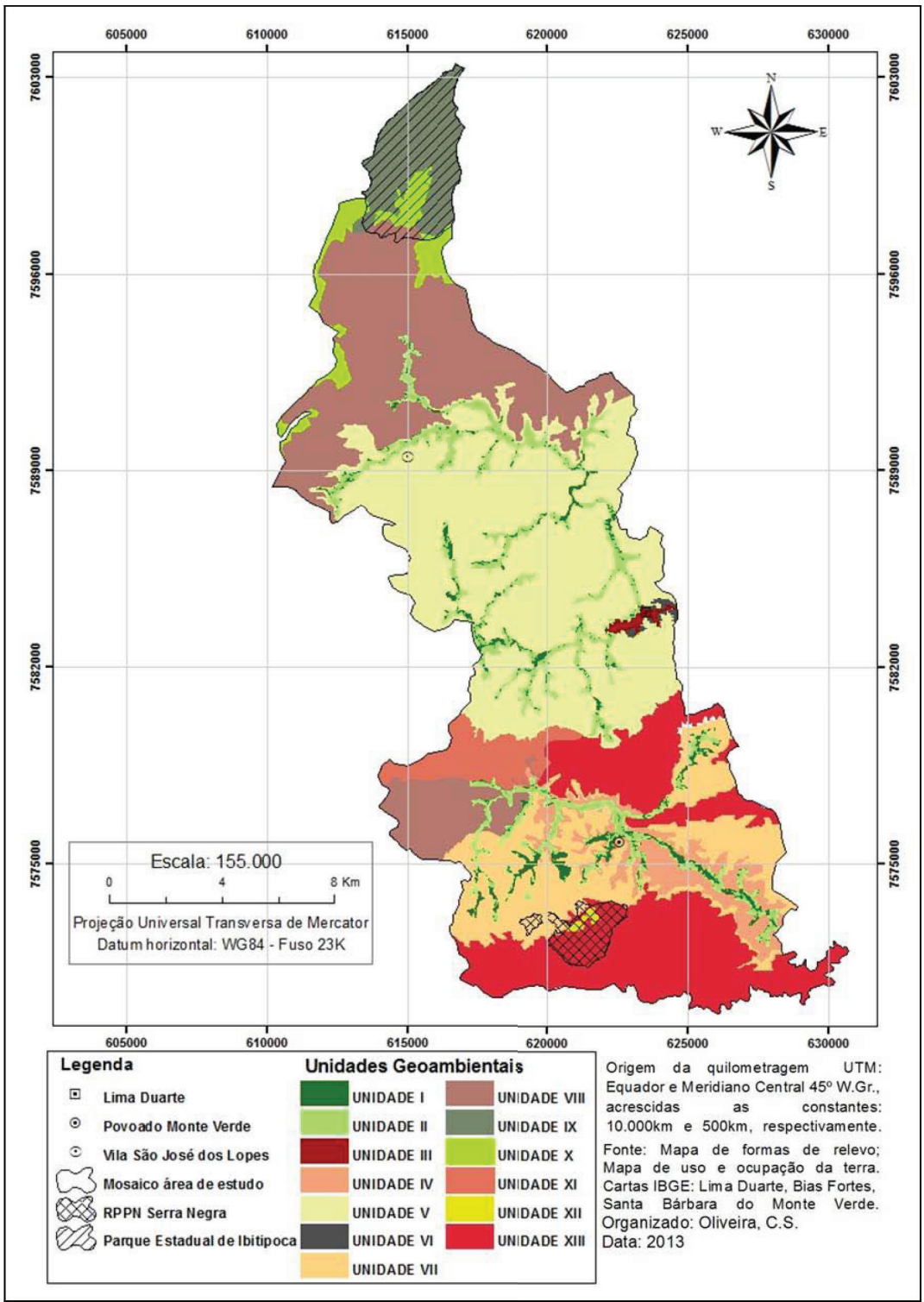

Figura 2 - Mapa de Unidades Geoambientais

Fonte: Mapa de formas de relevo; Mapa de uso e ocupação da terra. Cartas IBGE: Lima Duarte, Bias Forte, Santa Bárbara do Monte Verde. 
montana; unidade V - morros com encostas suavizadas e floresta estacional montana e pastagem; unidades VI - morros urbanizados intercalados com floreta estacional semidecidual montana; unidade VII - morros com floresta ombrófila montana e pastagem; unidade VIII - morros e serras baixas com floresta estacional semidecidual montana e pastagem; unidade IX - patamares de cimeira com campo rupestre de altitude em quartzíto; unidade X - patamares de cimeira com floresta estacional semidecidual montana; unidade XI - serras alongadas com floresta estacional semidecidual montana e pastagem; unidade XII - serras alongadas com complexo rupestre de altitude em quartzíto; unidade XIII- serras alongadas com floresta ombrófila.

\section{Unidade I - Planícies de Inundação Florestadas}

Como unidade I foram diferenciadas as planícies de Inundação com Floresta Estacional Semidecidual Aluvial e com Florestas exóticas de Eucaliptus e Pinus, ou seja, as áreas planas ou quase planas que margeiam os rios e córregos. Essa unidade apresenta diferentes composições litológicas, sendo os depósitos aluviais (areia, silte e argila) mais copiosos nas margens do Rio do Peixe, estes constituem os terrenos mais recentes da área. Nos trechos a montante, bacia hidrográfica do Rio do Salto, prevalece planícies estreitas com o canal do rio mais entalhado e com declividades mais acentuadas. Em contrapartida nas serras escarpadas da área, a maior parte da rede de drenagem é desprovida de planícies aluviais, enquanto que a jusante as planícies são mais largas. Os principais canais fluviais e seus afluentes que drenam a área vertem para o Rio do Peixe e para o Rio Monte Verde. São eles: Rio do Salto, Córregos dos Lopes, Córrego da Barra, Córrego Morro do Sal, Córrego Larangeiras, Córrego Floresta, Córrego Cantagalo, Córrego Bom Sucesso, Córrego da Praia, Córrego Limeira, Córrego Buriê, Córrego da Praia Gomes, Córrego Poço Triste, Córrego Vila, Córrego Sossego, Córrego Monte Alegre, Córrego Monte Verde, Córrego Tabuleiro, Córrego Serra Negra, Córrego Pilão, Córrego Andorinhas, Córrego Grande e Córrego da Serra. O padrão de drenagem apresenta disposição dos rios e córregos formando um engalhamento ou dendrítico.

Nesse geoambiente as condições edafoclimalógicas favorecem o desenvolvimento da vegetação hidrófila adaptadas a solos hidromórficos e higrófilas solos semi- hidromórficos, (RIZZINI, 1976), como é o 
caso das matas ciliares, embora esta esteja quase que completamente ausente em alguns trechos. A vegetação árborea mais representativa desse geoambiente está presente a leste do meandro do Rio do Peixe, nas coordenadas UTM ( $\mathrm{E}=622.319$ e $\mathrm{N}=7.587 .033)$, em altitude de 600 a 700 metros. Em outras áreas dessa unidade são mais conspícuas a presença de capoeirinhas e capoeiras em estágio inicial e médio de regeneração associadas ao abandono de áreas agrícolas. No que tange as planícies do Rio Monte Verde e seus tributários destaca-se as plantações de eucaliptos e, em alguns trechos, mata ciliar conservada.

\section{Unidade II - Planície de Inundação com vegetação rasteira}

Como unidade II, foram delimitados os terrenos correlacionados à planície de inundação com vegetação rasteira, igualmente distribuídos pelas planícies de inundação dos córregos mencionados na unidade I. O que diferencia essa unidade da anterior é a formação de vegetação rasteira.

De acordo com Ab’Sáber (2004), a correlação entre os diferentes solos com níveis de hidratação variados e os fatores altitudinais, no interior e na distribuição das planícies, fundamenta a diversidade de ecossistemas gerados na faixa complexa de transborde das águas fluviais. A camada de vegetação rasteira descontínua presente nesse geoambiente é composta por gramíneas nativas e exóticas não diferenciadas no mapeamento.

\section{Unidade III - Planície de Inundação urbanizada}

As áreas dessa unidade foram classificadas como as que concentram as infraestruturas urbanas, como: serviços, arruamentos, praças, calçamentos e estradas. Essa unidade situa-se em terrenos topograficamente planos a pouco ondulados, em declives que variam até 3\%. Nessa área localiza-se o núcleo urbano de Lima Duarte, sede do município. Torna-se oportuno ressaltar que o mosaico de paisagem em estudo equivale a $33,17 \%$ da área do munícipio que é de $381,87 \mathrm{~km}^{2}$. Segundo censo demográfico de 2010 do IBGE, a população de Lima Duarte é de 16.149 habitantes. Apesar de contar com uma população pouco expressiva e um baixo adensamento urbano, não ocupa extensas áreas da paisagem no mosaico, o núcleo urbano altera significativamente a dinâmica dos córregos e rios. Assim, devido à falta de infraestrutura adequada para 
tratamento de efluentes domésticos; altera a cobertura florestal necessária a sua implementação e altera o microclima devido às construções urbanas, geração de calor, poeira e outros poluentes atmosféricos decorrentes de atividades antropogênicas.

Não menos importante destacar é a presença da rodovia BR 267 nesse geoambiente. Essa rodovia é a principal via de conexão entre o sul e sudeste mineiro e é imprescindível para o desenvolvimento da região. Por outro lado, essa estrada é a principal barreira ao movimento da flora e fauna, sendo um dos principais agentes de desflorestação e fragmentação da paisagem (Liu et al., 2008; LAURANCE et al., 2002). Portanto, as áreas antrópicas atuam como barreiras aos processos ecológicos, pois subdividem populações e hábitats, conduzem espécies mais resistentes à degradação e são fontes de erosão, sedimentação, espécies exóticas e impactos humanos (Coimbra, 2006).

Unidade IV - Colinas e Morrotes com Floresta Ombrófila Montana intercalados com plantações de eucalipto e gramíneas exóticas

Esse geoambiente caracteriza-se por apresentar relevo ondulado e litologia de grafita granada biotita plagioclásio gnaisse e moscovita biotita xisto (Pinto et al.,1991). Essas rochas pertencem ao Grupo Andrelândia e datam do Proterozóico Médio. Repara-se a presença constante de pastagens intercaladas com a floresta ombrófila montana em diferentes estágios sucessionais. A distribuição da vegetação nessa área está restrita a pequenas e esparsas manchas intercaladas com pastagem formando um complexo mosaico de paisagem. São encontradas também áreas com formações pioneiras.

A principal vicissitude dessa unidade é sua favorabilidade ao uso agrícola em decorrência da disponibilidade hídrica e das condições do relevo como as menores amplitudes altimétricas e declividades de todo o mosaico.

Unidade V - Morros com encostas suavizadas e Floresta Estacional Semidecidual Montana e pastagem

Essa unidade constitui a maior área do mosaico, 33,54\% do total. Localiza-se sobre a característica paisagem formada principalmente de morros mamelonares, de contorno hemisférico e topos arredondados e 
encostas convexas. A litologia encontrada nessa unidade corresponde aos anfibólios, biotitas-anfibólios-plagioclásio-gnaisses bandados, do Complexo Juiz de Fora de idade arqueana e gnaisse trondhjemítico cinza claro, com intercalações de biotita e anfibólio, do Complexo Mantiqueira, do Proterozóico inferior (Pinto et al.,1991). Em consonância são encontrados solos antigos bem desenvolvidos como o latossolo vermelho amarelo distrófico.

As altitudes variam de 800 a 1500 metros e as declividades chegam a $25 \%$. Nesse geoambiente a floresta estacional semidecidual, Montana apresenta-se em um mosaico de manchas consorciadas com pastagens e interceptadas por estradas vicinais. Nesse setor, observa-se que a obrigação jurídica da averbação da reserva legal, assegura a permanência das manchas de vegetação nativa nas propriedades rurais da unidade. Em contrapartida, por causa da inexistência de vegetação ou atribuição de outros usos as áreas, nem todas as áreas de preservação permanente são materializadas como corredores ecológicos conforme orientação legal.

\section{Unidade VI - Morros urbanizados}

Essa unidade ocupa uma pequena área do mosaico, 0,20\%. Sua litologia é composta de gnaisses trondhjemítico cinza claro com lentes de biotita e anfibólio do Complexo Mantiqueira que datam do Proterozóico inferior (Pinto et al.,1991). O relevo é constituído por morros de topos arredondados com encostas convexas, côncavas e retilíneas. O processo de urbanização ocupa as encostas e morros dessa unidade, sendo seu principal elemento discriminador. O povoado de São José dos Lopes e de Monte Verde não apresentam características urbanas que permitissem seu enquadramento no mapeamento, além disso, a escala adotada no estudo imprimiu limitações quanto o enquadramento dessas pequenas e esparsas áreas rurais.

\section{Unidade VII - Morros com Floresta Ombrófila Montana e pastagem}

Essa unidade representa 9,43\% da área em estudo. A litologia composta por grafita-granada-biotita-plagioclásio-gnaisse e moscovita biotita xisto, (Pinto et al.,1991), condicionam um relevo fortemente ondulado com encostas côncavo-convexas e retilíneas. Os declives chegam a 45 \% 
em alguns setores e a altimetria varia de 8001000 metros. Seu principal componente vegetacional é a Floresta Ombrófila Densa Montana, embora esteja descontinua por toda área.

Em consonância com a remoção da vegetação nessa unidade observa-se o descuro com as encostas em áreas de relevo movimentado, acarretando os processos erosivos acelerado. Os reflorestamentos com espécies exóticas estão mais concentrados no setor sudoeste desse geoambeinte nas bacias hidrográficas dos córregos Grande e Monte Alegre, ainda que sejam visualizados em outros setores da área em menor concentração. As pastagens ocorrem por toda área ainda que apareçam menos expressivas que as formações florestais nos mapeamentos de uso da terra.

\section{Unidade VIII - Morros e Serras baixas com pastagem e Floresta Estacional Semidecidual Montana}

Esta unidade situa-se nas extremidades leste e oeste da área de estudo. Suas rochas são constituídas de biotita-plagioclásio-gnaisse intercalados com rocha calssilicastica, quartzito grosseiro e granada do Grupo Andrelândia e Complexo Mantiqueira (Pinto et al.,1991). O principal representante desse geoambiente é a Serra da Serrinha, cujas altitudes chegam a 1.200 metros, parte da Serra da Mantiqueira com altitudes até 1.300 metros, na nascente do córrego dos Lopes e Serra São João. Uma das características bem marcantes desse geoambiente são as exposições frequentes nas vertentes das serras das areias quartzosas decorrentes da desagregação mecânica dos quartzitos.

A distribuição geográfica das atividades econômicas nessa unidade geoambiental é desfavorável em virtude das condições do relevo, dos solos e da própria legislação, embora consiga algum êxito em setores menos declivosos das encostas. Ainda assim são encontradas áreas com pastagens abandonadas e processos de recolonização da vegetação pioneira.

Unidade IX - Patamares de Cimeira com Campo Rupestre de Altitude em Quartzito

Essa unidade geoambiental ocupa os topos aplainados da Serra do Ibitipoca, ou seja, sua morfologia dominante é formada por platôs quartzitos. O principal componente litológico é o quartzito grosseiro pobre em moscovita com intercalações de quartzito fino, posicionados em uma 
diversidade altimétrica que varia de $1.300 \mathrm{~m}$ e $1.784 \mathrm{~m}$ de altitude. O quartzito é constituído por aproximadamente 95\% de quartzo, 5\% de moscovita + clorita, com um pouco de zircão, opaco e feldspato. A foliação é marcada pela orientação planar preferencial dos grãos de quarzto, que geralmente mostram-se alongados em palhetas de moscovita (Pinto et al., 1997). Há amplas ocorrências de solos pouco desenvolvidos como os Cambissolos e Neossolos (Dias et al., 2002). A vegetação que ocupa esse platô são os complexos rupestres de altitude, constituídos frequentemente por gramíneas e subarbustos acostumados com as secas do inverno e com solos pobres pouco desenvolvidos. Nessa unidade existem inúmeras grutas esculpidas em quartzito que não foram individualizadas no mapeamento devido à escala de estudo.

\section{Unidade X - Patamares de Cimeira com Floresta Estacional Semidecidual Montana}

Nesse geoambiente os litotipos pertencem ao Grupo Andrelândia e datam do Proterozóico Médio, representados pelos quartzitos grosseiros pobre em moscovita com intercalações de quartzito fino (Pinto et al., 1997). A ocorrência da Floresta Estacional Semidecidual Montana em faixas altimétrica em torno de 1.300 metros justifica-se pelas melhorias nas características físicas dos solos (porosidade, drenagem, textura, umidade, profundidade e permeabilidade) pode compensar propriedades químicas ou biológicas adversas (Dias et al., 2002).

\section{Unidade XI - Serras alongadas com Floresta Estacional Semidecidual Montana e pastagem}

Esta unidade localiza-se na parte centro-sul da área. Os aspectos geológicos quanto à litologia e idade são idênticos aos discutidos nas unidades IX e X. Essa unidade se difere das anteriores quanto aos aspectos morfológicos e morfométricos e quanto às características de uso e ocupação da terra e aos aspectos vegetacionais. É o elemento que mais se destaca nesta paisagem, uma vez que é formatado por paredões de rochas quartzíticas, com altitudes elevadas que chegam a 1.400 metros. É representada por parte da Serra de Lima Duarte e Serra São João. O relevo é caracterizado por apresentar uma topografia irregular com vertentes de declividade acentuadas, em alguns trechos superiores a $45 \%$ e 
rampas íngremes convergentes para os vales a norte e a sul da serra. As principais áreas vegetadas desse geoambiente estão localizadas em torno das cabeceiras de drenagem dos córregos Tabuleiro, córrego da Serra e Monte Alegre.

Além do supracitado, essa unidade apresenta uma transição abrupta entre as serras que a configuram e os vales dos rios e córregos da área adjacente, tornando-se referência na paisagem, como é o caso do Pão de Angu.

\section{Unidade XII - Serras alongadas com Complexo rupestre de altitude em Quartzito}

Essa unidade geambiental ocupa uma área de 0,54\%. É constituída essencialmente de por uma litologia de quartzito grosseiro pobre em moscovita com intercalações de quartzito fino, (Pinto et al., 1997), posicionados em uma diversidade altimétrica que varia de $1.100 \mathrm{~m}$ e 1.600 m de altitude nas serras de Lima Duarte e Serra Negra.

As formações vegetacionais associadas a este tipo de litologia são Complexos Rupestres de Altitude, conforme designação de Benites et al. (2003). Esse geoambiente difere-se das outras unidades principalmente quanto às características geoecológicas dos ambientes onde ocorrem, como solos, relevo e clima, o que origina uma biota com altas taxas de diversidade e endemismos.

Unidade XIII - Serras alongadas com Floresta Ombrófila e pastagem

Esse geoambiente é formado por rochas metamórficas que datam do Proterozóico Médio, Grupo Andrelândia. Os principais representantes deste grupo na área são os quartzitos grosseiros que formam um relevo de serras escarpadas com aclives abruptos, marcadamente proeminentes na paisagem.

A Serra Negra, onde se localiza a RPPN de nome homônimo, parte da Serra de Lima Duarte e Serra do Pilão, constituem parte de um grande complexo de Serras da Mantiqueira enquadrado nesse geoambiente. Nessa unidade geoambiental destacam-se as elevações que chegam a 1.650 metros nos picos da Serra Negra e 1.400 na Serra de Lima Duarte. Os declives são mais acentuados na face orientada para o sul na Serra Negra e na face orientada para o norte na Serra de Lima Duarte, onde chegam a ser superiores a $45 \%$. Nessas áreas fortemente acidentadas, a vegetação é 
formada pela floresta ombrófila densa Montana, fortemente associada às condições edafoclimatólogicas diferenciadas.

São recorrentes a presença de grotas florestadas associadas e depressões cavadas pela erosão dos córregos da Serra Negra, Córrego Monte Verde e Córrego tabuleiro na Serra de Lima Duarte. Além disso, destacam-se na face orientada para norte da Serra Negra no lado leste, os sucos produzidos pela atuação da rede hidrográfica, caracterizando um relevo dissecado. De modo geral, a área ocupada por esta unidade está bem conservada e abriga expressivos representantes dos remanescentes da Mata Atlântica principalmente na face sul da Serra Negra.

Nesse geoambiente destacam-se as extrações de areia quartzosa usada na pavimentação das estradas rurais do município. Esses materiais geram solos muito arenosos e pobres, impróprios para agricultura. Nessas áreas os neossolos litólicos distrófico de textura arenosa, típico de relevo montanhoso e escarpado e os cambisssolos húmico distrófico de textura média e argilosa, de relevo forte ondulado e montanhoso predominam.

\section{Considerações Finais}

O conhecimento do padrão de organização e da estrutura da paisagem local e regional, no domínio do que ainda resta de Mata Atlântica preservada, é de extrema relevância para que se possa fazer um uso racional do seu potencial biótico, abiótico e paisagístico.

É nesse sentido, que se infere que os geoambientes identificados durante o trabalho, estruturam-se em diversas e sinuosas geoformas, em conjuntos exuberantes de formações florestais bem preservados e em alguns setores sobre complexos rupestres de altitude em quartzitos. Essas características singulares dessas paisagens montanhosas lhes conferem vocação restrita quanto ao uso e ocupação da terra, principalmente nos setores declivosos das escarpas das serras e nos patamares de cimeira, nas áreas marginais aos cursos d'água e nos topos de morro. De forma semelhante, as áreas de reserva legal distribuídas espacialmente por toda área nas propriedades rurais, visam primordialmente à preservação e manutenção do meio ambiente ecologicamente equilibrado, e também contam com proteção legislativa.

Não é de se surpreender que um estudo realizado pela Biota Minas (2010) tenha identificado a área adjacente ao Parque Estadual Ibitipoca 
como de relevância primordial para a conservação de invertebrados, mamíferos, aves, herpeto, peixes e flora no Estado de Minas Gerais. Essa posição é reflexo do quadro atual de desmatamento da Mata Atlântica, o bioma brasileiro que possui mais espécies ameaçadas de extinção, conforme as listas oficiais editadas pelo Ministério do Meio Ambiente.

É nesse contexto de destruição e desmatamento, extinção da fauna e da flora que fica realçado a relevância da área em estudo em termos de conservação e preservação de amostras significativas da Mata Atlântica e ecossistemas associados, bem como das paisagens formatadas pela associação dos diferentes elementos que a estruturam. Por outro lado, quando negligenciados e desconsiderados os padrões de organização e da estrutura da paisagem nas decisões de uso e ocupação da terra, assim como a questão da articulação de diferentes escalas geográficas no âmbito da complexidade da paisagem, no planejamento de rede de unidades de conservação, fomenta-se uma série de impactos ambientais negativos, muitos dos quais irreversíveis, ou então de complexas e onerosas soluções.

Advirta-se que os expressivos fragmentos florestais presentes nas áreas de complicada interferência antrópica, devido às características restritivas de um relevo acidentado e de difícil acesso, principalmente no que tange aos geoambientes X, XI, XII e XIII, configuram paisagens aptas a conservação e ao estabelecimento de corredores ecológicos (o que já os são em parte de domínio privado RPPN Fazenda Serra Negra e de domínio público o Parque Estadual do Ibitipoca); entretanto, somente elas não bastam para garantir a manutenção da biodiversidade. De acordo com Saito (1998) muitos animais requerem dois ou mais elementos de paisagem para viver, o que significa que utilizam os diferentes geoambientes, bem como os nutrientes, água e outros recursos ambientais nele inseridos de maneira diferenciada de acordo com suas adaptações morfofisiológicas.

Dessa forma, excetuando-se as ações antrópicas na área central do mosaico de paisagem onde está localizado parte do núcleo urbano de Lima Duarte, toda a área restante entre o domínio da RPPN Fazenda Serra Negra e do Parque Estadual do Ibitipoca, incluindo as RPPN's da Serra do Ibitipoca e Fazenda da Serra (4 e 22 ha respectivamente) viabilizam, em uma dimensão espacial mais ampla, a materialização do corredor ecológico da Mantiqueira.

Acrescente-se, portanto que não menos importante do que a conservação da biodiversidade, as paisagens inseridas no mosaico em estudo são um relevante patrimônio natural do Estado de Minas Gerais, atrativo 
ecoturístico e gerador de renda para as populações locais. Em suma, as análises realizadas no estudo, permitiram identificar e caracterizar unidades geoambientais, bem como realçar a importância dessas áreas e suas peculiaridades geoecológicas em um planejamento integrado da paisagem nas áreas de influência de unidades de conservação, fazendo interagir os diversos fatores conflitantes de uso e ocupação da terra.

\section{Referências}

AB'SÁBER, A. N. Os domínios de natureza no Brasil: potencialidades paisagísticas. São Paulo: Ateliê Editorial, 2003.

- O suporte geoecológico das Florestas Beiradeiras (Ciliares). In: RODRIGUES, R. R.; LEITÃO FILHO, H. F. Matas ciliares: conservação e recuperação. São Paulo: EDUSP/FAPESP, p.15-25, 2004.

BRASIL. Lei $n^{\circ}$ 9.985, de 18 de Julho de 2000. Institui o Sistema Nacional de Unidade de Conservação da Natureza e dá outras providências.

BENITES, V. M. et al. Solos e vegetação nos Complexos Rupestres de Altitude da Mantiqueira e do Espinhaço. Floresta e Ambiente, Viçosa, v. 10, n. 1, p. 7685, 2003.

BIOTA MINAS. Diagnóstico do Conhecimento sobre a Biodiversidade no Estado de Minas Gerais: Conservação, uso e Biotecnologia - Subsídio ao Projeto Biota Minas. Governo do Estado de Minas Gerais, 2010.

COIMBRA, V. B. C. A ecologia da paisagem e estratégias para ocupação e uso do solo: o entorno da RPPN santuário do Caraça. 2006. 227 f. Dissertação (Mestrado em Arquitetura e Urbanismo) - Faculdade Arquitetura e Urbanismo, Universidade Federal de Minas Gerais. Belo Horizonte, 2006.

DIAS, H .C. T. et al. Geoambientes do Parque Estadual do Ibitipoca, município de Lima Duarte-MG. Revista Árvore, 2002, v. 26, p. 777-786.

INSTITUTO BRASILEIRO DE GEOGRAFIA E ESTATISTICA. Censo Demográfico 2010. Disponível em: < http://www.censo2010.ibge.gov.br>. Acesso em: 08 jan. 2013.

. Manual Técnico de Uso da Terra. 2. ed. Rio de Janeiro: IBGE, 2006.

IPT. INSTITUTO DE PESQUISAS TECNOLÓGICAS. Mapa geomorfológico do estado de São Paulo. São Paulo, 1981.

LAURANCE, W. F. et al. Predictors of deforestation in the Brazilian Amazon. Journal of Biogeography, v. 29, p. 737-748, 2002.

LARDOSA, E.I. Metodologia para mapeamento e detecção de mudanças nos remanescentes de Mata Atlântica do Estado do Rio de Janeiro, a partir de imagens do satélite Landsat 7 ETM+ estudo de caso: parque Estadual do Desengano. Rio de Janeiro, 2005. 90 f. Dissertação (Mestrado em Engenharia da Computação) 
- Faculdade de Engenharia da Computação, Universidade do Estado do Rio de Janeiro, Rio de Janeiro, 2005.

LIU, S. L. et al. Evaluating the influence of road networks on landscape and regional ecological risk - A case study in Lancang River Valley of Southwest China. Ecological Engineering, v. 34, p. 91-99, 2008.

PINTO, C. P. et al. Programa de Levantamentos Geológicos Básicos do Brasil. Lima Duarte. Folha sf-23-X-C-VI, Estado de Minas Gerais, Escala 1:100.000. MIEDNPM, CPRM, Belo Horizonte, Mapas e texto explicativo, 1991, 224 p.

RIZZINI, C. T. Tratado de Fitogeografia do Brasil. São Paulo: Hucitec, 1976, 274 p.

SAITO, C. H. O estruturalismo na ecologia da paisagem. Brazilian Journal of Ecology, Rio Claro, SP, Brazil, v. 2, n. 1, 1998.

SANTOS, R. F. Planejamento Ambiental: teoria e prática. São Paulo: Oficina de textos, 2004. 184 p.

SNUC. SISTEMA NACIONAL DE UNIDADES DE CONSERVAÇÃO DA NATUREZA. Lei $n^{o}$ 9.985, de 18 de julho de 2000. Brasília: MMA/SBF, 2000. 32 p.

TORRES, F. T. P.; MARQUES NETO, R.; MENEZES, S.O. Introdução à Geomorfologia. São Paulo: Cengage Learning, 2012. 322 p.

TURNER, M. G. Landscape ecology: the effect of pattern on process. Annual review of Ecology and Systematics, n. 20, p. 171-197, 1989

VALENTE, A. S. M.; GARCIA, P. O.; SALIMENA, F. R. G. Zona da Mata Mineira: aspectos fitogeográficos e conservacionistas. In: OLIVEIRA, A. P. L. de P. (Org.). Arqueologia e patrimônio da Zona da Mata mineira. Juiz de Fora: Editar Editora Associada Ltda, 2006. p. 79-92..

VEDOVELLO, R. Aplicações da Cartografia Geotécnica e Geoambiental no Planejamento Urbano. In: SIMPÓSIO BRASILEIRO DE CARTOGRAFIA GEOTÉCNICA E GEOAMBIENTAL, 5., 2004. São Carlos, SP. Mesa redonda. São Carlos, SP: ABGE, 2004.

Cristina Silva de Oliveira - Possui Graduação em Geografia pela Universidade Federal de Juiz de Fora. Mestrado pelo programa de pós-graduação em Geografia pela Universidade Federal de Juiz de Fora. Atualmente é Doutoranda em Geografia pela Universidade Estadual Paulista Júlio de Mesquita Filho.

Recebido para publicação em 20 de setembro de 2016 Aceito para publicação em 25 de outubro de 2016 